\title{
Study on Brand Name Translation from the Perspective of Cultural Difference
}

\author{
Jing Yang \\ Wuhan Qingchuan University, Wuhan, Hubei, China
}

Keywords: Brand Name Translation; Cultural Differences; Principles; Techniques.

\begin{abstract}
Along with the economic globalization, more enterprises have been active in the global market. Brand name stands for the commodities' quality and the enterprises' image, which not only conveys commodities' information to the foreign customers, but also transfers their cultural connotation. Due to the fact that brand name is attached to different cultures, brand name translation is substantially equivalent to a kind of intercultural communication. And a good brand name translation needs to combine both the excellent translation techniques and intercultural communication. From the perspective of cultural differences, the thesis specifically analyzes the cultural influence on Chinese and English brand name translation by many examples, and it focuses on the existing problems, the principles, and the techniques of brand name translation. In translation process, cultural differences should be given priority.
\end{abstract}

\section{Introduction}

\subsection{Brand and Its Name}

According to the European Community Trademark Regulation, "the brand is a name, symbol, sign, design, number or some combination of these elements used to identify commodities or services of the enterprise." and "A brand has been granted solely for its owner and has been given legal protection." The basic definition shows the essence and main characteristic of brand, and the most essential elements in brand should contain as follows:1) it suggests the advantages, qualities and characteristics of the commodity. 2) It is easy for recognizing, reading, and memorizing. 3) It should distinguish the products of one enterprise from others. 4) Registered brand are protected by law.

Brand name, as the most important part of brand, is expressed in words, which contains most of the information of the commodities. In some degree, a brand name represents for a company's image, reflecting the enterprise culture and its credit. With the competition in global market, brand names embody different cultures. Customers can recognize and confirm the producers or providers through brand names, and they are the direct way to arouse customers' interest so as to promote sales. What's more, brand names are the direct advertisement of a enterprise and one of the most effective ways to arouse the potential customers' interest so as to promote sales [1].

Therefore, a good brand name is especially important to the enterprise. The thesis mainly focus on the brand name translation.

\subsection{Brand Name Translation}

With the development of the global economy, China has become the most potential markets around world. At the same time, to compete with foreign products, many Chinese products have entered into the international market. To participate in international competition, Chinese products must set up the good image and create a good business reputation. And a good brand name can not only attract consumers' attention, but also have a great impact on the development of the enterprises. Then, how to accurately translate the brand name becomes a question for all.

Translation is an interlingual and intercultural communication. Since language and culture are inseparable, brand, as a special form of language, often reflects culture, customs, economy, politics, religions and cultural aesthetics. Brand in communication has irreplaceable function of social pragmatics. In order to accurately translate the brand, the translators are required not only to have 
good language skills, but also to possess comprehensive knowledge of interlanguage and intercultural communication. If translators are able to learn cultural differences, they can realize the true sense of the equivalent translation.

\section{Existing Problems in Brand Name Translation}

Translation is a transfer between cultures, and cultural differences are sometimes big obstacles to achieve successful translation. When translating, the translators should consider cultural factors prior, or cultural differences may lead to some problems in brand name translation [2].

\subsection{Tendency of Chinese "Pinyin"}

At present, some translators often directly translate the Chinese brand with Pinyin. For the lack of popularity of the Chinese brand, translators simply translate Chinese brand to English language country consumers, which can not express the deep connotation. For example, the Chinese brand, "Ai Qi" washing machine, is meaningful for the Chinese people. The husband buys this brand of washing machine to express his love to his wife; At the same time, everytime the wife sees or uses the washing machine, she also associates it with the husband for his love. When the washing machine's English name is directly translated to "Ai Qi" Washing Machine", the connotation of love is lost in translation, without any cultural information.

Besides, sometimes using Pinyin in brand name translation not only causes difficulty in conveying the original Chinese meaning, but also brings up misunderstanding of the target consumers'. The Chinese Pinyin and English words are the combination of letters, their spellings sometimes easily coincide. If Chinese Pinyin words correspond to bad English words, in this case, brand name translation can not express the original good feeling. For example, a translator put a baby talcum powder into "Fangfang" Baby Talcum Powder. "Fang" in Chinese means "fragrant", while in English it means "the snake's teeth". It is unpersuasive for mothers to buy such a powder for their babies.

\subsection{Mechanical word-for-word Translation}

Even if equivalence can be used in brand name translation, it does not guarantee that the consumers can understand the original meanings, because consumers tend to understand the content with their own cultural background. Due to the different cultural connotation of words and lack of understanding, equivalence from word-for-word translation can not reach the successful informing purpose. For example, a bicycle, produced in Guangzhou, is named "Wu Yang". Here "Wu Yang" represents for auspicious things in Chinese, and "Yang" in Chinese corresponds to "ram" in English, which is a symbol of Guangzhou. In addition to this memorial significance, "Yang" in Chinese culture means gentle, kind, loving and helpful. However, when the bikes are sold to foreign markets, the brand name is translated into "Five Rams". And the meaning of ram in English is different from that in Chinese. "Ram" in English has the meaning of "collision", and "Five Rams" as the brand name of the bicycle let consumers associate it with car accident which does not give people a sense of security, English consumers will not buy this brand of bicycle naturally.

Cultural differences exist in many aspects, and different cultures will produce connotative and associative meanings in translation. Therefore, the translator must consider the consumers' psychological factors from different cultural backgrounds, otherwise successful brand name translation can not be achieved. For instance, the "Kong Que" color TV set is translated into "Peacock" Color TV. In China, the peacock is a symbol of beauty, "Peacock" for television's brand naturally alludes to the color TV with realistic view and high quality. Unfortunately, the English nation usually considers "Peacock" as a filthy or obscene bird representing for bad luck. So "Peacock" as a brand name will damage the image of the merchandise in English countries.

\section{The Principles of Brand Name Translation}

Brand is just like the name of a person. And it becomes more and more important with the expansion of the exchange of goods. Many international famous brands have already become the 
enterprise's intangible assets and tremendous wealth. Today, with rapid increasing of the international trade, brand tends to become international, and a good brand name can promote the sales of the products. Brand name translation is not a simple translation from one language to another language, it involves many factors such as culture, customs, habits, and so on. Brand name translation should not only reflect the commodities' information, but also embodies enterprises' intelligence, contains a wealth of culture and reflects the psychological needs of consumers in general. So some principles in brand name translation are introduced as follows:

\subsection{The Principle of Grasping the Characteristic of Commodities}

Brand is a reflection of commodity and an important advertisement. Therefore, if the translation of brand name can expound commodity's performance in some aspects, it will make consumers impressed. For example: "Pampers" translated as "Bang Bao Shi" shows that the products can help mothers attend to the baby, making the baby more comfortable and happier, and it is full of love to a baby; "Comfortable" translated as "Jin Fang", embodies the categories of commodities, showing its good performance. The Chinese famous brand "Wei Wei Dou Nai" is translated as "Soybean", in which "Bean" refers to the soybean, and it reflects the attributes of the product.

\subsection{The Principle of Respecting the Target Customers' Psychology and Customs}

Human's life has been influenced by culture in different aspects. Culture restricts and limits the process of people's experience, and people perceive the world on the basis of culture. Some stereotypes affect people's values, psychology and imagination. Therefore, the translation of brand name must balance the target consumer's culture and aesthetic psychology. For example, a kind of pillow's brand called "Yuan Yang", its original translation is "Mandarin Ducks". In Chinese culture, "Yuan Yang" means a pair of lovers who are deeply in love with each other, while in English "Mandarin Ducks" is just a bird's name without such a beautiful figurative meaning. However, in the extended meaning of English "Lovebirds" is similar to Chinese "Yuan Yang". So we can translate the brand name into "Lovebirds Pillow" instead of "Mandarin Ducks Pillow". Since brand name translation conveys cultural connotation, its metaphorical meaning can not be ignored.

Import commodities' brand name translation also needs to take Chinese culture into account. Chinese love to use the lucky words or commendatory words, so when translating import brands, translators should pay more attention to make a choice of words which meet the needs of Chinese consumers' aesthetics and psychology. "Anyway", the famous daily consumer goods, is translated as "An Li" in China. From the pronunciation, "An Li" reads easily, and brings people the feeling of pleasure. At the same time, "An Li" brings Chinese consumers a sense of safety, quality and convenience.

\subsection{The Principle of Following the Target Customers' Political and Historical Culture}

When translating brand name, translators may often face difficulties about politics, history and other problems. So they must give up using words which easily lead to negative associations. For the maintenance of the target country's dignity, translators should have certain understanding of the politics, the history and so on. Here is an example of the shampoo translation. "Poison" is a brand of shampoo, and the word "poison" means "toxin" or "noxiousness". To name the shampoo as "Poison" is a kind of reverse thinking. According to some experts, some women are fond of a wild taste from foreign market, and the well-designed Poison Shampoo sells best and attracts women of all ages from many countries. As for the Chinese tradition, women are fond of a graceful, implicit beauty rather than the wild taste. To develop the Chinese market, translating the shampoo as "Bai Ai Shen" to Chinese consumers is really an excellent work, which obeys cultural habits and pragmatic principles.

\subsection{The Principle of Achieving Maximization of Aesthetic Translation}

"Coca-Cola" is translated as "Ke Kou Ke Le". But few people will ask why it is translated in this way? The "Coca" and "Cola" are the two names of plants, and the coca's leaf contains cocaine (sometimes used as a local anesthetic, but also widely used as drugs for its excitement and stimulation). Such a frightening name is used on a drink, why its translation is thought to be a 
successful one? Its success lies in retaining the alliterative loud pronunciation and completely abandoning the original meaning, and it is so tactical to show the pleasant drink feelings. Even though the taste of this kind of drink isn't good for everyone, even many people think it tastes like a traditional Chinese medicine, the translation claims that the taste is delicious and drinking it will make people feel happy.

\section{Some Techniques of brand name translation}

Brand name translation is not only a language conversion when the brand is used as one kind of special advertising carried out cross-border publicity. And it requires translators to notice the social and economic factors, culture and customs as well as other factors. What's more, it emphasizes international advertising culture. Therefore, the translators have to learn the commodity culture, international advertising and marketing culture to understand the different cultural backgrounds, their psychological needs, spiritual ethos and aesthetics of the consumers'. In translation practice, the commonly used translation techniques mainly include transliteration, literal translation, liberal translation, combinative translation and non-translation.

\subsection{Transliteration}

Transliteration maintains the pronunciation and emphasizes the original main functions of the source language. Though transliteration is simple, it can not only retain the original rhyme, but also well reflect the brand's cultural connotation. What's more, it can bring up attraction and improve the product's popularity. So many brand names are translated by transliteration.

Pure Transliteration. Pure transliteration is loyal to the original brand name translation. In Chinese pronunciation, pure transliteration is mainly applicable to our country's names, merchandises with ethnic style. For example, Chinese "Maotai" liquor has a long history, and it is famous in the world. For Chinese phonetic alphabet is difficult to achieve the internationalization, it is still purely transliterated as "Moutai". In this way, it is helpful for the enterprise to compete in international market.

For some pronunciations of English brand names, translators basically use Chinese characters with corresponding syllable, ignoring the exact Chinese meaning. For instance, "Lincoln" is translated into "Lin Ken", "Canon" is translated as "Jia Neng", "Kodak" is translated into "Ke Da", "Puma" is translated into "Biao Ma", "Parker" is translated as "Pai Ke". They are all translated by using pure transliteration. Those brand name translations soon will be able to catch the attention of customers though not that meaningful in Chinese.

Homophonic Transliteration. Homophonic transliteration chooses lucky words to compose a new brand name translation in the synonyms in order to adapt to customer's cultural psychology orientation. The translation method pays attention to tone, pattern, and meaning. For example, a soap called "Safeguard" is translated into "Shu Fu Jia", "Shu" gives a refreshing and comfortable feel; "Fu" means "skin", which shows the commodity's function; "Jia" expresses the using effect. A medicine called "Quick", is translated to "Kuai Ke" in Chinese, which is reminiscent to the fact that the medicine will quickly overcome disease. And there are so many examples like "Avon" is translated as "Ya Fang", "Tide" is translated into "Tai Zi", and so on.

\subsection{Literal Translation}

According to Peter Newmark, "in literal translation, grammatical constructions of the source language are converted to their equivalents in the target language, but the lexical words are translated out of context"[3]. In some sense, literal translation not only keeps the original content, but also keeps the original form, especially the original metaphor, image and national, local characteristics, if necessary. Although there are many cultural differences, some brand names can be literally translated directly. For example: a red mine brand "Dynasty" is translated as "Wang Chao" in Chinese, and the brand name translation reminds the consumers of history, so as to stimulate consumer's desire to purchase them.

If brand names contain same information or concepts in Chinese and western cultures, and they 
can almost be translated literally. The literal translation usually uses common words, animal names, scenery, flowers or commendatory term, for instance, "The Great Wall" brand is not only a product made in China, but also a symbol of human miracle.

\subsection{Liberal Translation}

Liberal translation is also called paraphrasing translation, namely using similar and related words to translate brand name in the target language pronunciation. Liberal translation has the features of being vivid and impressive, which retains the original meaning. What's more, liberal translation is able to deliver the aesthetic and value orientation of the products. Here are some instances such as "Rejoice", its translation is "Piao Rou". Rejoice means joy and happiness, and the brand name translation indicates hair will become smooth after using the shampoo. So translators fully explore its connotations of the brand name. "Pioneer" is a famous brand of an electric company in Japan, the translation of the brand name is "Xian Feng", which reflects the commodity quality with first-class technology.

\subsection{Combinative Translation}

Combinative Translation is a combination of transliteration, literal Translation and liberal translation. For example, the "Goldlion" is translated into "Jin Li Lai", which is a good translation. As we all know, "lion" means "Shi Zi"'" in Chinese, but the pronunciation of "Lion" is similar to the Chinese "Shi", and "Shi" means "Lose" in Chinese, then the businessmen will think "lose" unlucky. When it is translated as "Jin Li Lai", it means wealth and good luck, and the consumers' psychology is met satisfyingly. "Benz" is a famous German automobile brand, the original brand name is "Mercedes-Benz". If using transliteration method to translate, it may be translated as "Mei Sai De Shi-Ben Ci". Although it is loyal to the source language, there is no cultural connotation, and it also cannot achieve the expected effect of translation for marketing. When it is translated as "Ben Chi", it means driving fast without any limits.

\subsection{Non-translation}

Due to the differences in Chinese and English, sometimes it is impossible to apply the translation methods above to translate the brand names. So it is necessary to use non-translation method. Non-translation avoids using the equivalences in the target language and leave the original ones untranslated [4]. There are some brand names unifying intercultural communications by short forms which have great stability and maintain the original and profound meaning at any time. When translating this kind of brand, translators usually take non-translation approach to retain the original letters, symbols or Arabic numerals.

We are all familiar with the "555" cigarettes, "999"medicines, "IBM" computers, "TCL" electronic products, "LG" Electronics and so on. However, trying to choose non-translation of these brand names still needs to pay attention to the principle of localization. Some English brand names are translated directly into Chinese Pinyin, which might be a failure caused by cultural differences. Therefore, when translators choose non-translation method, they should try to avoid the culture conflict on the brand name translation of commodity in the target countries.

\section{Conclusions}

Translation is a comprehensive process. Due to the different thinking modes, values and orientations of the target consumers', translators must fully take the target consumers' cultural background into account, which includes not only the target consumers' linguistic features, but also their religious beliefs, values, attitudes and customs and many other cultural factors. Brand name translation is not only a simple replacement between two languages, but also a cultural combination in two different languages.

From this thesis, the following conclusions can be reached:

First, brand name is heavily related with culture. To achieve the purpose of brand name translation, the translators should give priority to the cultural differences between the source country and the 
target country and well understand the cultural connotations in the process of brand name translation.

Second, the existing problems in brand name translation is directly related to the ignorance of culture factors in the target market. To solve the problems relies on the consciousness of intercultural communication.

Third, the translators should choose appropriate translation techniques in brand name translation such as transliteration, literal translation, liberal translation, combinative translation, non-translation and so on. No matter which technique is used, cultural factors should be considered preferentially in translation.

Brand name relates to the image of the enterprise and business opportunities, which is vital for the source countries to further explore the international market. To achieve successful brand name translation, cultural differences should be given priority in translation process.

\section{References}

[1] Ma Lihua, Trademark Translation in Intercultural Communication [D], Sichuan University, 2007.

[2] Whilss, Wolfram, The Science of Translation: Problems and Methods[M], Shanghai: Shanghai Foreign Languages Education Press, 2001

[3] Newmark, P. Approaches to Translation[M], Shanghai: Shanghai Foreign Language Education Press, 2001.

[4] Qiu Yiru, Translatability and Non-translation[J], Chinese Translators Journal.2001. 